\title{
A Modified Single-Phase Transformerless Z-Source Photovoltaic Grid-Connected Inverter
}

\author{
Hongpeng Liu ${ }^{\dagger}$, Guihua Liu*, Yan Ran*, Gaolin Wang*, Wei Wang*, and Dianguo $\mathrm{Xu}^{*}$ \\ ${ }_{\dagger}^{\dagger}{ }^{*}$ Department of Electrical Engineering, Harbin Institute of Technology, Harbin, China
}

\begin{abstract}
In a grid-connected photovoltaic (PV) system, the traditional Z-source inverter uses a low frequency transformer to ensure galvanic isolation between the grid and the PV system. In order to combine the advantages of both Z-source inverters and transformerless PV inverters, this paper presents a modified single-phase transformerless Z-source PV grid-connected inverter and a corresponding PWM strategy to eliminate the ground leakage current. By utilizing two reversed-biased diodes, the path for the leakage current is blocked during the shoot-through state. Meanwhile, by turning off an additional switch, the PV array is decoupled from the grid during the freewheeling state. In this paper, the operation principle, PWM strategy and common-mode (CM) characteristic of the modified transformerless Z-source inverter are illustrated. Furthermore, the influence of the junction capacitances of the power switches is analyzed in detail. The total losses of the main electrical components are evaluated and compared. Finally, a theoretical analysis is presented and corroborated by experimental results from a 1-kW laboratory prototype.
\end{abstract}

Key words: Common-mode voltage, Leakage current, Photovoltaic power system, Power loss, Pulse width modulation, Z-source inverter

\section{INTRODUCTION}

For PV grid-connected systems, two types of inverters are usually used. One is a dc/ac inverter with a line-frequency transformer and the other is a dc/ac inverter with a dc/dc converter. This line-frequency transformer can boost the voltage after the dc/ac inverter and guarantee galvanic isolation between the grid and the PV system [1]. However, because of its low frequency $(50-60 \mathrm{~Hz})$, this transformer is big, heavy and expensive [2]. Therefore, a high frequency dc-dc converter with a high-frequency transformer is used to boost the voltage to reach a constant value [3], [4]. Unfortunately, the high-frequency transformer and switches in the $\mathrm{dc} / \mathrm{dc}$ converter will cause additional power loss. As a result, the interest in single-stage transformerless conversion topologies has grown.

In single-stage topologies, the Z-source inverter is one of the best choices to realize inversion and boost functions in a single stage [5]-[7]. It has some advantages such as a simple structure, high reliability of the inverter to avoid the influence

Manuscript received Jan. 7, 2015; accepted May 4, 2015

Recommended for publication by Associate Editor Pat W. Wheeler.

†Corresponding Author: 1hp602@hit.edu.cn

Tel: +86-451-86403230, Fax: +86-451-86413420, Harbin Inst. of Tech.

*Dept. of Electrical Engineering, Harbin Institute of Technology, China of shoot-through due to EMI, and little output waveform distortion. However, the isolation capability has to be considered carefully because of the removal of the transformer. The traditional Z-source inverter topology with its PWM techniques can generate a high-frequency three-level CM voltage, whose peak value is equal to the Z-source capacitor voltage stress. Because of the capacitance between the PV panel and the ground, the high-frequency potential difference can cause undesirable leakage currents in transformerless PV systems [8]. The additional leakage currents can increase the grid current ripples, system losses, and (conducted and radiated) electromagnetic interferences [9]-[11]. Thus, a novel transformerless Z-source inverter topology and a particular PWM strategy should be researched to reduce leakage current in order to meet the strict grid codes established by authorities. For example, a $300 \mathrm{~mA}$ threshold level is stated in the DIN VDE 0216 standard [12].

Recently many research works have been proposed to eliminate the leakage current to meet this standard. These leakage current reduction techniques can be mainly divided into two groups. One is a group of galvanic isolation techniques, and the other is a group of CM voltage clamping techniques.

The galvanic isolation topologies introduce dc-decoupling and ac-decoupling methods to disconnect PV systems and the 
grid during zero states [13]. H5 and H6 belong to the dc-decoupling topology family. The H5 topology, which is used in SMA (SMA Solar Technology AG) commercial converters, adds only one switch when compared to full-bridge (FB) inverters [14]. The H6 topology, which is proposed in [15], symmetrically adds two additional switches to the FB inverter. The H6 topology equally distributes the device's efforts and balances the thermal distribution. In [16], a novel H6 topology is proposed, which constructs a new direct power passing path in a half cycle to reduce the conduction loss. The highly efficient reliable inverter concept (HERIC) topology applies a bidirectional switch to realize the disconnection of the converter and the grid during zero-voltage vectors [17]. Due to the reduction of switches, the ac-decoupling method can provide lower power losses in the conduction path. Although the topologies mentioned above have a simple circuit structure, the galvanic isolation cannot completely eliminate the leakage current due to the influence of switches' junction capacitances and the parasitic parameters of the leakage current loop [15].

To completely eliminate the leakage current, the $\mathrm{CM}$ voltage should be clamped to half of the input voltage during the zero state, which can keep the CM voltage constant for all of the switching modes. This clamping technique has been used in the oH5 [18], modified H6 topologies [19], HB-ZVR [20] and HBZVR-D [21]. By connecting one pole of a PV cell directly to the neutral line of the grid, the leakage current can be eliminated. In [22], the negative pole of a PV array is directly connected to the neutral line of grid. In [23], the positive terminal of a PV array is connected to the phase output during the positive half-wave and to the neutral terminal during the negative half-wave. In addition, the neutral point clamp (NPC) inverter [24] connects the midpoint of a PV array to the neutral of a grid, which achieves three or more output levels. However, the NPC inverter, like the half-bridge inverter, demands a higher input voltage.

In this paper, a modified single-phase transformerless Z-source inverter (ZSI-TL) with one decoupling switch and two fast-recovery diodes is presented to eliminate the ground leakage current. In addition, a special PWM strategy is proposed to avoid zero states with the two lower switches conduction. Furthermore, it can ensure that each phase leg switches on and off once per switching cycle, and it can make the shoot-through zero states evenly allocated into each phase. Moreover, it is analyzed that the junction capacitances of the switches can influence the CV voltage, and a corresponding paralleled capacitor of the switch is designed. Hence, the path for the leakage current can be blocked by two reverse-biased diodes during the shoot-through state, while the CM voltage remains constant during the non-shoot-through state. Therefore, the leakage current is eliminated.

The paper is organized as follows. Section II introduces the
ZSI-TL, its PWM strategy and the corresponding operation mode. Section III illustrates the leakage current reduction principle, while Section IV analyzes the system losses. Section V shows some experimental results, and Section VI draws some conclusions.

\section{OPERATION PRINCIPLES OF THE MODIFIED TOPOLOGY}

\section{A. Structure of the Modified ZSI-TL}

Fig. 1 shows the ZSI-TL by using the dc-decoupling method. When compared with the traditional single-phase Z-source grid-connected inverter, the ZSI-TL adds one additional switch $\left(S_{5}\right)$ and one fast-recovery diode $\left(D_{2}\right) . S_{5}$ is used to electrically decouple the PV array from the grid during the zero state, while $D_{1}$ and $D_{2}$ are used to block the path of the leakage current during the shoot-through state.

\section{B. Modified PWM Strategy}

The PWM strategy is one of the key factors that affects the leakage current. To achieve the aim of eliminating the leakage current of the ZSI-TL, the modulation strategy of the traditional single-phase Z-source inverter needs to be modified. For Z-source inverter modulation, the shoot-through states are added to the null intervals to keep the active interval constant. In order to ensure that only one single device is switched during every state transition, the shoot-through states are added adjacent to the instants of the state transitions of a conventional voltage-source inverter. According to the ZSI-TL topology structure, the zero states where $S_{2}$ or $S_{4}$ conducts must be forbidden to eliminate the leakage current in the modified PWM strategy. Therefore, to achieve the aim of boosting the dc-link voltage, the shoot-through states should be added between the active sates and the zero states where $S_{1}$ or $S_{3}$ conducts.

As an illustration, Fig. 2 shows the switching patterns of the ZSI-TL. Here, $S_{1}$ is ON and $S_{2}$ is OFF during the positive half cycle. Sinusoidal reference signals are used to modulate $S_{3}$. $S_{4}$ and $S_{5}$, with additional shoot-through time intervals added, commutate complementarily to $S_{3}$. Similarly, during the negative half cycle, $S_{3}$ is $\mathrm{ON}$ and $S_{4}$ is OFF. $S_{1}$ commutates at the switching frequency. $S_{2}$ and $S_{5}$, with additional shoot-through time intervals added, commutate complementarily to $S_{1}$. It should be noted that each phase leg continues to switch on and off once per switching cycle. Without changing the total zero-state time interval, the shoot-through zero states are evenly allocated into each phase.

Assuming that the inductors $L_{Z 1}$ and $L_{Z 2}$ have the same inductance $(L)$ and that the capacitors $C_{Z 1}$ and $C_{Z 2}$ have the same capacitance $(C)$, the Z-source network becomes symmetrical. As a result, the following formula can be obtained as: 


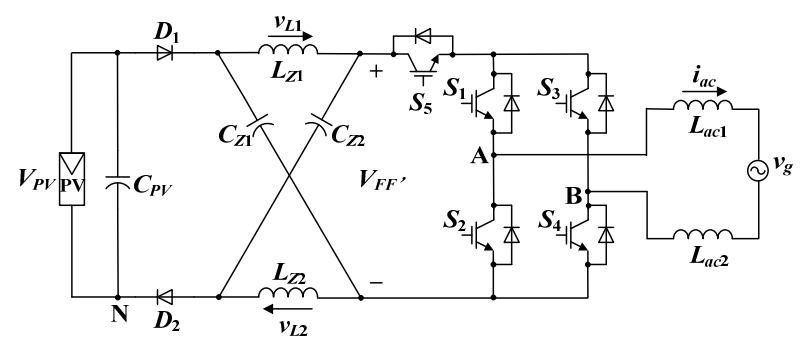

Fig. 1. Single-phase transformerless Z-source grid-connected PV inverter.

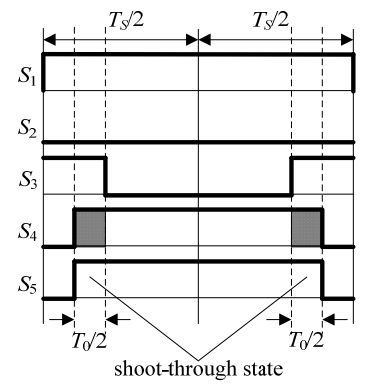

(a)

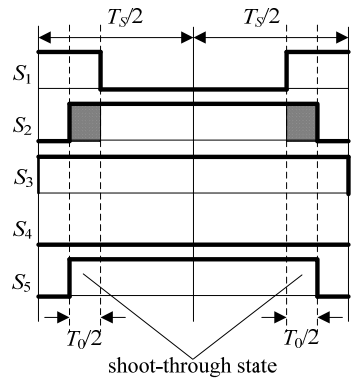

(b)
Fig. 2. Modulation strategy of ZSI-TL. (a) During the positive half cycle. (b) During the negative half cycle.

$$
V_{C 1}=V_{C 2}=V_{C} \text { and } v_{L 1}=v_{L 2}=v_{L}
$$

According to the modified PWM strategy, the shoot-through duty ratio $d_{0}$ should be limited to $1-M$.

Therefore, the output peak voltage of the inverter can be expressed as:

$$
\hat{v}_{a b}=\hat{V}_{F F}, M=\frac{T_{S}}{T_{1}-T_{0}} V_{P V} M=\frac{M}{1-2 d_{0}} V_{P V}=B M V_{P V}
$$

where $\hat{V}_{F F^{\prime}}$ is the peak dc-link voltage, $V_{P V}$ is the output voltage of the PV panel, $M$ is the modulation index, and $T_{0}$, $T_{1}$ and $T_{S}$ are the shoot-through time interval, the non-shoot-through time interval and the switching cycle, respectively. Equation (2) shows that the output voltage can be stepped up or down by choosing an appropriate boost factor, $G$,

$$
G=B M \text {. }
$$

If $M=1-d_{0}$, the relation between $M$ and the maximum value for $G$ can be obtained as:

$$
G_{\max }=\frac{M}{2 M-1} .
$$

Thus, to boost the output voltage, $M$ ranges from 0.5 to 1 .

\section{Operation Mode Analysis}

Fig. 3 shows the operation modes of the ZVI-TL.

1) Mode 1 is the freewheeling mode during the positive half cycle of the grid voltage. $S_{1}$ and $S_{3}$ are ON while $S_{2}, S_{4}$ and $S_{5}$ are OFF. The diodes $D_{1}$ and $D_{2}$ are conducting and the Z-source inductor current decreases linearly. The anti-parallel diode of $S_{3}$ conducts. Therefore, $u_{A B}=0 \mathrm{~V}$ and the output current decreases through the switch $S_{1}$ and the anti-parallel diode of $S_{3}$.

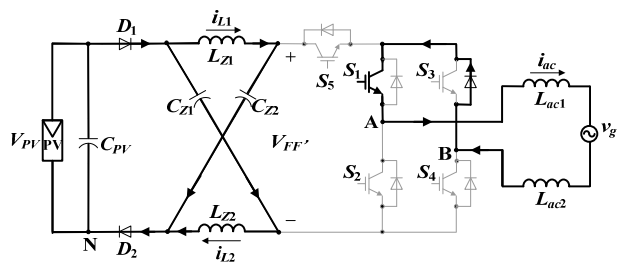

(a)

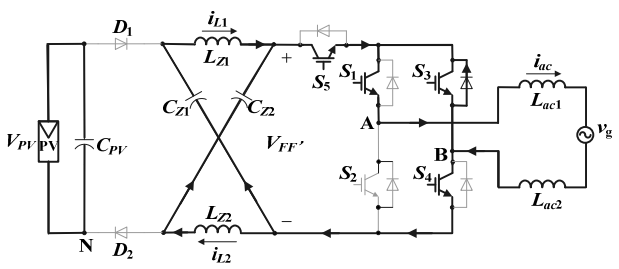

(b)

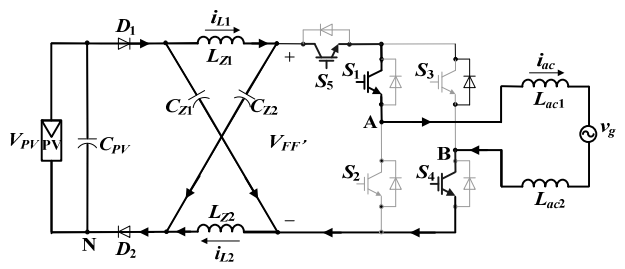

(c)

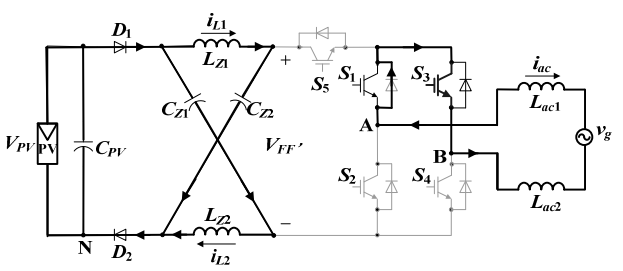

(d)

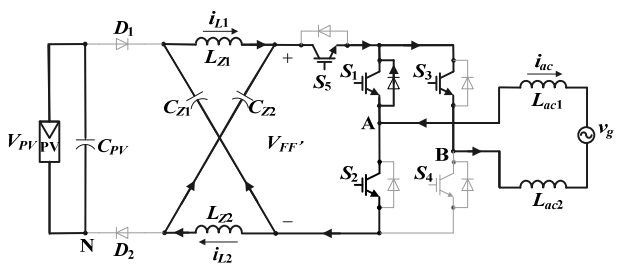

(e)

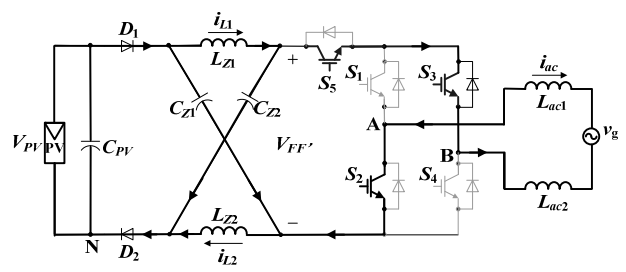

(f)

Fig. 3. Six operation modes of ZVI-TL. (a) Mode 1. (b) Mode 2. (c) Mode 3. (d) Mode 4. (e) Mode 5. (f) Mode 6.

2) Mode 2 is the shoot-through mode during the positive half cycle of the grid voltage. $S_{1}, S_{3}, S_{4}$ and $S_{5}$ are ON while $S_{2}$ is OFF. The sum of the Z-source capacitors voltage is greater than the dc source voltage $\left(V_{C 1}+V_{C 2}>V_{P V}\right)$, the diodes $D_{1}$ and $D_{2}$ are reverse-biased, and the $\mathrm{Z}$-source capacitors charge the $\mathrm{Z}$-source inductors. 
The Z-source inductor current increases linearly, while the output current $i_{\mathrm{ac}}$ decreases.

3) Mode 3 is the active mode during the positive half cycle of the grid voltage. $S_{1}, S_{4}$ and $S_{5}$ are ON while $S_{2}$ and $S_{3}$ are OFF. The output current increases through the switches $S_{5}, S_{1}$ and $S_{4}$.

4) Mode 4 is the freewheeling mode during the negative half cycle of the grid voltage. $S_{1}$ and $S_{3}$ are ON while $S_{2}, S_{4}$ and $S_{5}$ are OFF. The diodes $D_{1}$ and $D_{2}$ are conducting. The Z-source inductor current decreases linearly. Therefore, $u_{A B}=0 \mathrm{~V}$ and the output current decreases through the switch $S_{3}$ and the anti-parallel diode of $S_{1}$.

5) Mode 5 is the shoot-through mode during the negative half cycle of the grid voltage. $S_{1}, S_{2}, S_{3}$ and $S_{5}$ are ON while $S_{4}$ is OFF. The diodes $D_{1}$ and $D_{2}$ are reversed-biased, and the Z-source capacitors charge the Z-source inductors. The Z-source inductor current increases linearly, while the output current decreases.

6) Mode 6 is the active mode during the negative half cycle of the grid voltage. $S_{2}, S_{3}$ and $S_{5}$ are ON while $S_{1}$ and $S_{4}$ are OFF. The output current increases through the switches $S_{5}, S_{3}$ and $S_{2}$.

From the above analysis, it can be seen that the shoot-through states are evenly inserted between the active states and the traditional zero states. The zero states freewheel only through $S_{1}$ and $S_{3}$.

\section{LEAKAGE CURRENT ANALYSIS OF THE ZSI-TL}

\section{A. Model of the CM Voltage}

Fig. 4(a) shows the CM model for the ZSI-TL including the most significant stray elements. The most important stray elements that influence the leakage current dynamics include the stray capacitance between the PV array and the ground $C_{P V g}$ and the series impedance between the ground connection points of the inverter and the grid $Z_{p g}$. The leakage current $i_{\mathrm{cm}}$ flows through the closed-loop path consisting of $C_{P V g}$, the $Z$-source network, the bridge, the filters $\left(L_{a c 1}\right.$ and $\left.L_{a c 2}\right)$, the utility grid, and $Z_{p g}$. Without $Z_{p g}$ considered, the total $\mathrm{CM}$ voltage $v_{t c m}$ is defined as:

$$
v_{t c m}=\frac{v_{A N}+v_{B N}}{2}+\frac{L_{a c 2}-L_{a c 1}}{2\left(L_{a c 2}+L_{a c 1}\right)}\left(v_{A N}-v_{B N}\right)
$$

where $v_{A N}$ represents the voltage between terminal (A) and terminal $(\mathrm{N})$, and $v_{B N}$ represents the voltage between terminal (B) and terminal $(\mathrm{N})$.

From (5), if $L_{a c 1}=L_{a c 2}$, the total $\mathrm{CM}$ voltage is only relevant to $v_{A N}$ and $v_{B N}$. The CM voltage $v_{c m}$ can be given by the following:

$$
v_{c m}=\frac{v_{A N}+v_{B N}}{2} .
$$

$v_{A N}$ and $v_{B N}$ are determined by the PWM strategy of the ZSI-TL. Therefore, $v_{A N}$ and $v_{B N}$ can be regarded as the controlled-voltage sources connected to the negative terminal

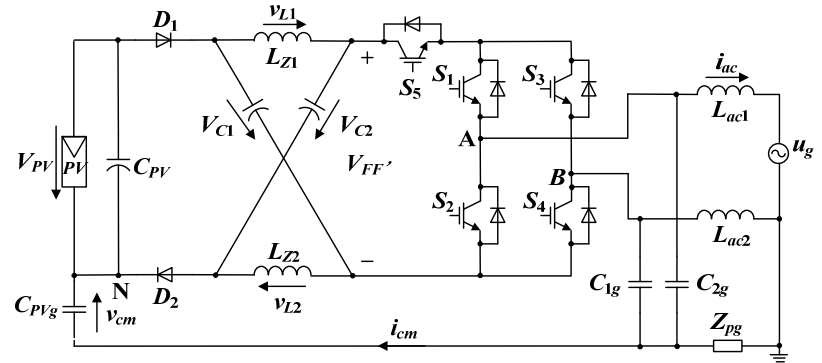

(a)

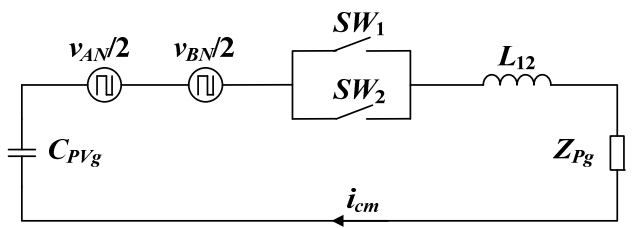

(b)

Fig. 4. Common-mode model for ZSI-TL. (a) Full model. (b) Simplified model.

of the PV array, namely a square-wave voltage sources with a switching frequency. The simplified circuit of Fig. 4(b) is finally obtained. $S W_{1}$ and $S W_{2}$ represent the diodes of the ZSI-TL. $S W_{1}$ and $S W_{2}$ are ON during the non-shoot-through states, and they are OFF during the shoot-through states. $L_{12}$ is obtained by the following:

$$
L_{12}=\frac{L_{a c 1} L_{a c 2}}{L_{a c 1}+L_{a c 2}} .
$$

In the active modes (Mode 3 and Mode 6), the CM voltage can be expressed as:

$$
v_{c m}=\frac{v_{A N}+v_{B N}}{2}=\frac{V_{C}+V_{P V}-V_{C}}{2}=\frac{V_{P V}}{2}
$$

where $v_{A N}=V_{C}$ and $v_{B N}=V_{P V}-V_{C}$ (Taking Mode 3 as an example.).

In the freewheeling modes (Mode 1 and Mode 4), the CM voltage can be obtained as:

$$
v_{c m}=\frac{v_{A N}+v_{B N}}{2}=\frac{\frac{V_{P V}}{2}+\frac{V_{P V}}{2}}{2}=\frac{V_{P V}}{2}
$$

where $v_{A N}=v_{B N}=\frac{v_{F F^{\prime}}}{2}+v_{L}=\frac{2 V_{C}-V_{P V}}{2}+V_{P V}-V_{C}=\frac{V_{P V}}{2}$.

In the shoot-through modes (Mode 2 and Mode 5), the sum of the two Z-source capacitors' voltage is greater than the output voltage of the PV panel. Therefore, the diodes $D_{1}$ and $D_{2}$ are reverse biased. $S W_{1}$ and $S W_{2}$ are OFF so that the path for the leakage current is blocked.

According to the above analysis, because the CM voltage is kept constant during the non-shoot-through states and the discharge path of the $\mathrm{CM}$ voltage is blocked during the shoot-through states, the leakage current is avoided.

\section{B. Influence of the Junction Capacitances}

In the active mode, the dc and ac sides of the inverter are directly connected by the filter inductors. The operation states 
and the common-mode voltage are not affected by the junction capacitance of the switches. In the freewheeling mode, the PV panel is disconnected from the grid by $S_{5}$, and the CM voltage is affected by the junction capacitances of the switches. In the shoot-through mode, because the path of the leakage current is blocked, the influence of the junction capacitances will not be considered. Therefore, when the inverter commutates from the shoot-through mode to the freewheeling mode, the slope of the voltages $v_{A N}$ and $v_{B N}$ depends on the junction capacitance of the switches, and the CM voltage $v_{c m}$ is accordingly affected.

Taking the commutation from Mode 2 to Mode 1 as an example, there are two stages. The other commutation, from Mode 5 to Mode 4, is similar due to the symmetry of the operation modes.

Stage I: Fig. 5 shows the transient circuit of the commutation from Mode 2 to Mode 1 , where $C_{D 1}$ and $C_{D 2}$ represent the junction capacitances of the diodes $D_{1}$ and $D_{2}$, $C_{1} \sim C_{5}$ represent the junction capacitors of the switches $S_{1} \sim S_{5}$ and $D_{3}$ represents the anti-parallel freewheeling diode of $S_{3}$. When $S_{4}$ and $S_{5}$ are turned OFF, the two charging or discharging circuits are composed of the junction capacitors $C_{2}, C_{4}$ and $C_{5}$. According to Kirchhof's current law, the following current equations can be obtained:

$$
\begin{aligned}
& i_{1}=i_{C 5}+i_{D 3} \\
& i_{2}=i_{C 4}+i_{D 3} \\
& i_{C 2}=i_{1}-i_{2}
\end{aligned}
$$

where $i_{1}$ and $i_{2}$ represent the currents of the two charging or discharging circuits; $i_{D 3}$ is the current of $D_{3}$; and $i_{C 2}, i_{C 4}$ and $i_{C 5}$ are the currents of $C_{2}, C_{4}$ and $C_{5}$, respectively.

From (10) to (12), the formula can be derived as follows:

$$
i_{C 5}=i_{C 2}+i_{C 4} \text {. }
$$

Assuming that the acquired charge of $C_{D 2}$ is equal to the discharged charge of $C_{D 1}$, an equivalent circuit model for the transient state can be obtained in Fig. 5(b), where the initial potentials in stage 1 are indicated in the brackets (the node $N^{\prime}$ is used as a reference potential). It is obvious that the junction capacitors $C_{2}$ and $C_{4}$ are charged by $C_{5}$ in parallel through the filter inductors $L_{a c 1}$ and $L_{a c 2}$. Thus, the voltages $v_{A N}$ and $v_{B N}$ rises until their values are equal to $V_{P V} / 2$, and the transient process on Stage 1 ends. Fig. 5(c) shows an equivalent circuit model at the end of Stage 1. Based on the charge conservation, it can be found that:

$$
\left(V_{C}-\frac{V_{P V}}{2}\right) C_{5}=\left[\frac{V_{P V}}{2}-\left(V_{P V}-V_{C}\right)\right]\left(C_{2}+C_{4}\right)
$$

As a result, the relation of the junction capacitors can be obtained as:

$$
C_{5}=C_{2}+C_{4}
$$

Stage II: Fig. 6 shows a potential resonant circuit in Mode 1 according to (15). The voltages $v_{A N}$ and $v_{B N}$ become $V_{P V} / 2$ synchronously only if $C_{5}=C_{2}+C_{4}$ at the end of transient state I. Therefore, the $\mathrm{CM}$ voltage can still remain $V_{P V} / 2$. The

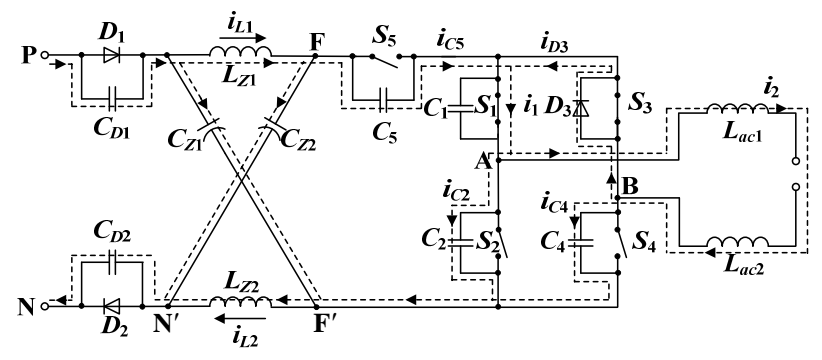

(a)

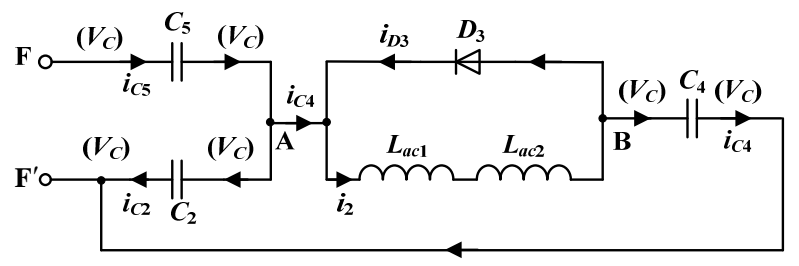

(b)

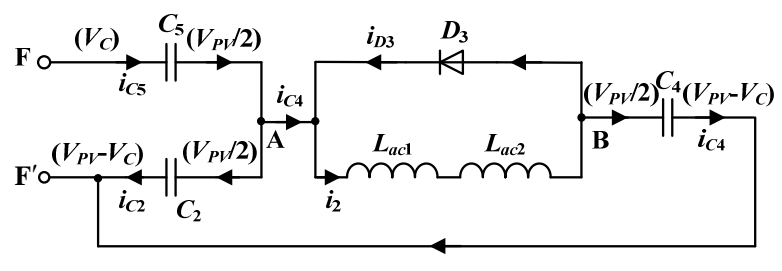

(c)

Fig. 5. Transient circuit of commutation from Mode 2 to Mode 1. (a) Transient circuit. (b) Equivalent circuit from Mode 2 to Mode 1. (c) Equivalent circuit at the end of Stage 1.

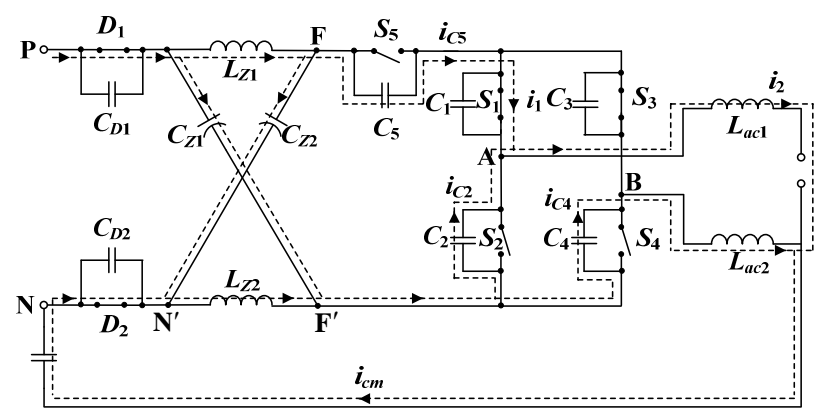

Fig. 6. Potential resonant circuit in Mode 1.

modified inverter can operate normally in Mode 1, and the condition for eliminating the leakage current is met as analyzed earlier.

\section{POWER LOSS CALCULATION AND ANALYSIS}

\section{A. Conduction Losses Analysis}

Assuming that the output current is sinusoidal:

$$
i_{a c}=I_{C M} \sin \alpha \text {. }
$$

where $i_{a c}$ is the output current, and $I_{C M}$ is the peak value of the output current.

The conduction losses of $S_{1}$ can be obtained in the positive half cycle as: 


$$
\begin{aligned}
P_{S 1_{-} \text {con }} & =\frac{1}{2 \pi} I_{C M} \int_{0}^{\pi}\left(\frac{V_{C E N}-V_{C E O}}{I_{C N}} I_{C M} \sin ^{2} \alpha+V_{C E O} \sin \alpha\right) d \alpha \\
& =\frac{1}{4} \frac{V_{C E N}-V_{C E O}}{I_{C N}} I_{C M}^{2}+\frac{1}{\pi} V_{C E O} I_{C M}
\end{aligned}
$$

where $V_{C E O}$ is the saturation voltage drop, $I_{C N}$ is the rated current, and $V_{C E N}$ is the collector-to-emitter voltage at the rated current. This implies a threshold voltage plus a resistance drop.

In the negative half cycle, the conduction losses of $S_{1}$ during the shoot-through time interval are:

$$
\begin{aligned}
P_{S 1_{-} S H} & =\frac{1}{2 \pi} \int_{0}^{\pi}\left(\frac{V_{C E N}-V_{C E O}}{I_{C N}} \times 2 I_{L}+V_{C E O}\right) 2 I_{L} d_{0} d \alpha \\
& =\left(2 \frac{V_{C E N}-V_{C E O}}{I_{C N}} I_{L}+V_{C E O}\right) I_{L} d_{0}
\end{aligned}
$$

where $I_{L}$ is the Z-source inductor current.

Another part of the conduction losses of $S_{1}$ is induced by the conduction of the body diode in the negative half cycle.

$$
\begin{aligned}
P_{S 1_{-} D 1} & =\frac{1}{2 \pi} \int_{0}^{\pi}(1-M \sin \alpha)\left(\frac{V_{F N}-V_{F O}}{I_{C N}} i_{a c}+V_{F O}\right) i_{a c} d \alpha \\
& =\left(\frac{1}{4}-\frac{2 M}{3 \pi}\right) \frac{V_{F N}-V_{F O}}{I_{C N}} I_{C M}^{2}+\left(\frac{1}{\pi}-\frac{M}{4}\right) V_{F O} I_{C M}
\end{aligned}
$$

where $V_{F O}$ is the saturation voltage drop, and $V_{F N}$ is the diode voltage drop at the rated current.

Thus, the average conduction losses of $S_{1}$ are:

$$
P_{S 1_{\_} \text {all }}=P_{S 1_{-} \text {con }}+P_{S 1_{-} D 1}+P_{S 1_{-} S H} \text {. }
$$

In a similar way, the average conduction losses of $S_{2}$ can be given as:

$$
P_{\mathrm{S} 2 \_a l l}=P_{\mathrm{S} 2 \__{-} \text {con }}+P_{\mathrm{S} 2 \_\mathrm{SH}}
$$

where:

$$
\begin{aligned}
P_{S 2_{2} \text { con }} & =\frac{1}{2 \pi} M I_{C M} \int_{0}^{\pi}\left(\frac{V_{C E N}-V_{C E O}}{I_{C N}} I_{C M} \sin ^{2} \alpha+V_{C E O} \sin \alpha\right) \sin \alpha d \alpha, \\
& =\frac{2 M}{3 \pi} \frac{V_{C E N}-V_{C E O}}{I_{C N}} I_{C M}^{2}+\frac{M}{4} V_{C E O} I_{C M} \\
P_{S 2_{2} S H} & =\frac{1}{2 \pi} \int_{0}^{\pi}\left(\frac{V_{C E N}-V_{C E O}}{I_{C N}} \times 2 I_{L}+V_{C E O}\right) 2 I_{L} d_{0} d \alpha . \\
& =\left(2 \frac{V_{C E N}-V_{C E O}}{I_{C N}} I_{L}+V_{C E O}\right) I_{L} d_{0}
\end{aligned}
$$

According to Fig. 2, the conduction losses of $S_{3}$ are equal to those of $S_{1}$, and the conduction losses of $S_{4}$ are equal to those of $S_{2}$. In addition, the conduction losses of $S_{5}$ are the sum of $S_{2}$ and $S_{4}$. Therefore, the conduction losses of the switches are:

$$
\begin{aligned}
P_{\text {all }} & =P_{S 1 \_a l l}+P_{S 2 \_a l l}+P_{S 3 \_a l l}+P_{S 4 \_a l l}+P_{S 5 \_a l l} . \\
& =2 P_{S 1 \_a l l}+4 P_{S 2 \_a l l}
\end{aligned}
$$

\section{B. Switching Losses Analysis}

The turn-on losses, turn-off losses and recovery power losses of $S_{1}$ can be calculated from (23) to (25), respectively.

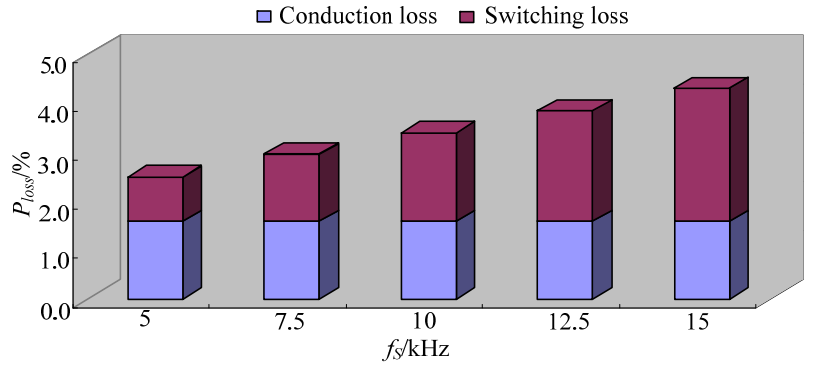

Fig. 7. Power switches loss distribution for ZSI-TL.

$$
\begin{gathered}
P_{S 1_{-} O N(A V)}=\frac{\left(2 V_{C}-V_{P V}\right) I_{L}^{2} t_{r N}}{I_{C N}} f_{S} \\
P_{S 1_{\_} O F F(A V)}=\frac{1}{3}\left(2 V_{C}-V_{P V}\right) I_{L}\left(1+\frac{I_{L}}{I_{C N}}\right) t_{f N} f_{S} \\
P_{S 1_{-} r r}=\frac{1}{2}\left(2 V_{C}-V_{P V}\right) t_{r r N} f_{S}\left(0.8+0.4 \frac{I_{L}}{I_{C N}}\right) \\
\times\left(0.35 I_{r r N}+0.3 \frac{I_{L}}{I_{C N}} I_{r r N}+2 I_{L}\right)
\end{gathered}
$$

where $f_{S}$ is the switching frequency, and $t_{r N}$ and $t_{f N}$ are the rise and fall times of the switch at a rated current, respectively. $t_{r r N}$ is the diodes reverse recovery time, and $I_{r r N}$ is the peak reverse recovery current.

Thus, the switching losses of $S_{1}$ can be expressed as follows:

$$
P_{S 1_{-} S_{-} \text {all }}=P_{S 1_{-} \mathrm{ON}(\mathrm{AV})}+P_{\mathrm{S1}_{-} \mathrm{OFF}(\mathrm{AV})}+P_{\mathrm{S1}_{-} r \mathrm{r}} \text {. }
$$

In a similar way, the average switching losses of $S_{2}$ can be given as:

$$
P_{S 2 \_s \_a l l}=\frac{1}{3} P_{S 1 \_S_{-} \text {all }} .
$$

The switching losses of $S_{3}$ are equal to those of $S_{1}$, and the switching losses of $S_{4}$ are equal to those of $S_{2}$. In addition, the switch state of $S_{5}$ is the same as that of $S_{4}$ in the positive cycle and it is also the same as that of $S_{2}$ in the negative cycle. However, the voltage across $S_{5}$ is doubled when compared with $S_{2}$ or $S_{4}$. As a result, the switching losses of $S_{5}$ are quadrupled when compared with $S_{2}$. The total switching losses of the switches are:

$$
P_{S_{-} \text {all }(\mathrm{AV})}=2 P_{S_{1} S_{-} \text {all }}+6 P_{S_{2} S_{-} \text {all }}=4 P_{S_{1} S_{\text {s_all }}} \text {. }
$$

By substituting the parameters from the datasheets of an IRGP4062DPbF [25], the total losses with the change of the switching frequency are calculated. The efficiency evaluation of the ZVI-TL is shown in Fig. 7. The output power of the $\mathrm{PV}$ inverter is $1 \mathrm{~kW} . V_{P V}=320 \mathrm{~V}, V_{g}=220 \mathrm{~V}, M=0.775$, and $d_{0}=0.1$. When the switching frequency is low, the switching losses are not the main source of the power losses. However, as the switching frequency increases, the distribution of the switching losses increases gradually and becomes the main source of power losses. A lower switching frequency leads to a high total harmonic distortion (THD) of the output current. Therefore, in view of the quality of the output current and the 


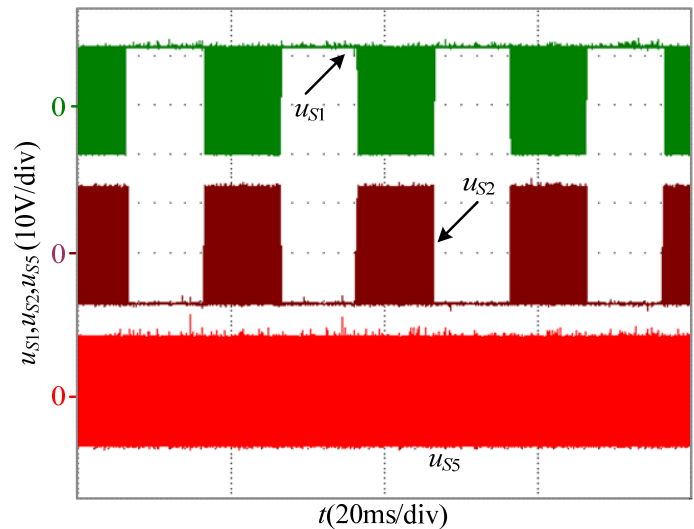

Fig. 8. Gating signals of switches.

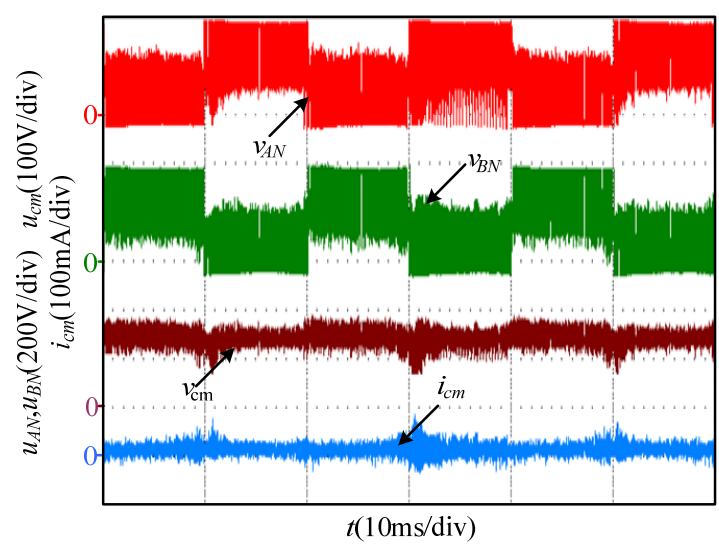

(a)

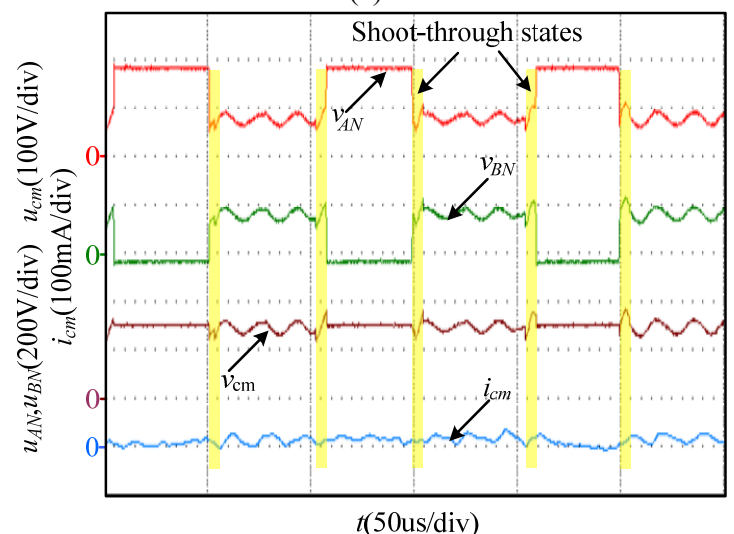

(b)

Fig. 9. Experimental waveforms of $\mathrm{CM}$ voltage and leakage current with paralleled capacitor. (a) Experimental waveforms in the grid cycle. (b) Experimental waveforms in the PWM cycle.

switching losses, a compromised switching frequency of $10 \mathrm{kHz}$ is selected in this paper.

\section{EXPERIMENTAL RESULTS}

A $1 \mathrm{~kW}$ prototype circuit has been designed and tested to verify the performance of the proposed ZVS-TL topology.

The detailed components and parameters are as follows: input voltage, $V_{P V}=320 \mathrm{~V}$; Z-source capacitor voltage, $V_{C}=360 \mathrm{~V} ;$ Z-source capacitor, $C_{Z 1}=C_{Z 2}=940 \mu \mathrm{F} ;$ Z-source

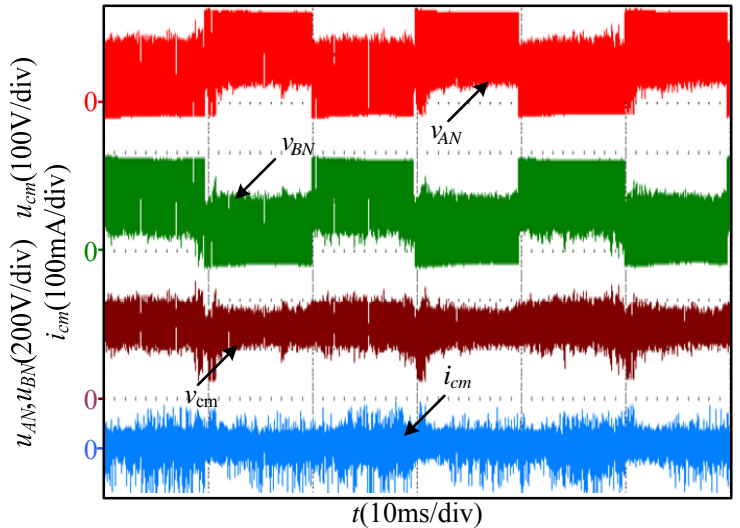

(a)

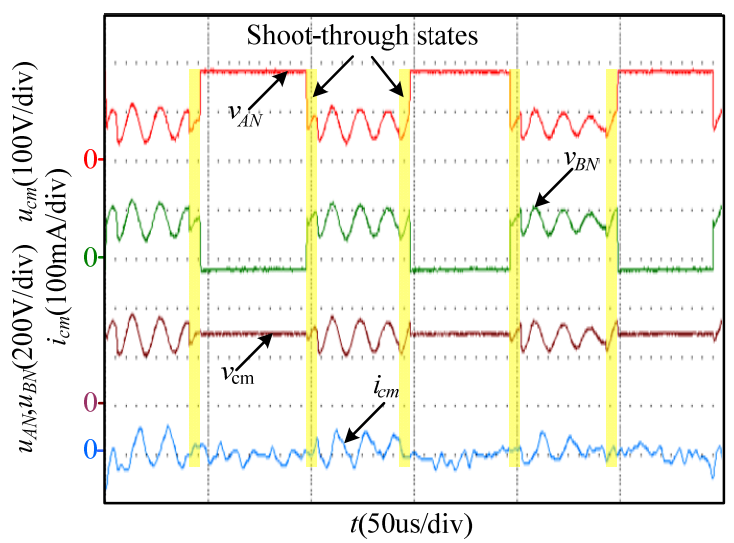

(b)

Fig. 10. Experimental waveforms of CM voltage and leakage current without paralleled capacitor. (a) Experimental waveforms in the grid cycle. (b) Experimental waveforms in the PWM cycle.

inductor, $L_{Z 1}=L_{Z 2}=4 \mathrm{mH}$; filter inductor, $L_{a c 1}=L_{a c 2}=4.5 \mathrm{mH}$; grid voltage, $V_{g}=220 \mathrm{Vac}$; grid frequency, $f_{g}=50 \mathrm{~Hz}$; switching frequency, $f_{S}=10 \mathrm{kHz}$; parasitic capacitor, $C_{P V g}=0.1 \mu \mathrm{F}$; power switches, $S_{1}-S_{5}=$ IRGP4062DPbF; and junction capacitors of the switches, $C_{1}-C_{5}=84 \mathrm{pF}$.

The experimental gating signals in a grid cycle are shown in Fig. 8. It can be seen that the experimental gating signals $u_{s 1}, u_{s 2}$ and $u_{s 5}$ agree with the analysis results of the PWM scheme, and that the gating signals of $u_{s 2}$ and $u_{s 5}$ are synchronized well in the negative half cycle.

According to the principle of the junction capacitors, one additional capacitor with a value of $84 \mathrm{pF}$ should be paralleled to $S_{5}$. In addition, a capacitor with a values of $82 \mathrm{pF}$ is applied in this prototype circuit. Because $Z_{p g}$ is very small, it is not considered. The $\mathrm{CM}$ voltage and the leakage current waveforms of the ZVI-TL with a paralleled capacitor in the grid-cycle and in the PWM cycle are shown in Fig. 9(a) and Fig. 9(b). The yellow highlighted sections represent the shoot-through states. From (8) and (9), $v_{A N}=360 \mathrm{~V}, v_{B N}=-40 \mathrm{~V}$ in Mode 3, and $v_{A N}=v_{B N}=160 \mathrm{~V}$ in mode 1. By choosing a reasonable value for the paralleled capacitor, $82 \mathrm{pF}$, $v_{A N}=v_{B N}=0.5 V_{P V}$ is obtained at the ending point of the transient process from the shoot-through mode to the freewheeling 


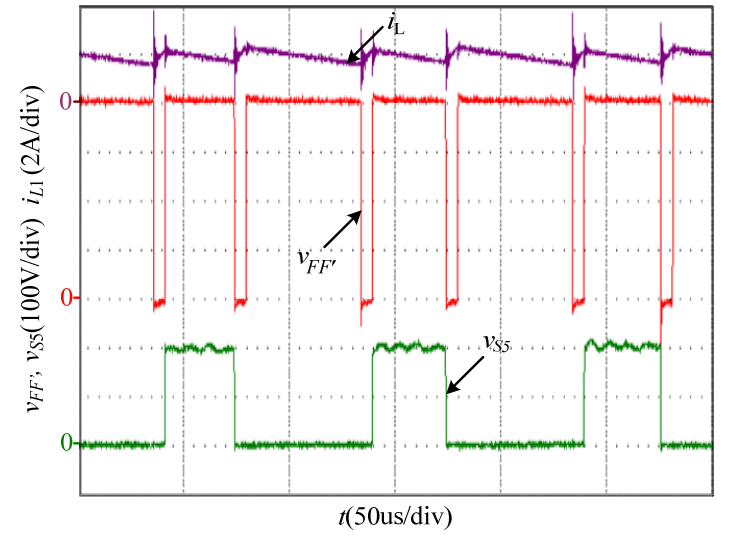

Fig. 11. Experimental waveforms of $v_{F F}, v_{S 5}$ and $i_{L}$.

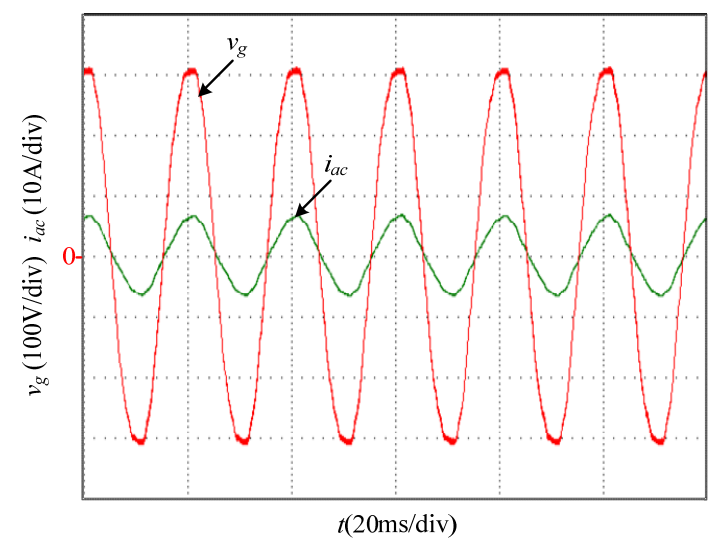

Fig. 12. Experimental waveforms of $v_{g}$ and $i_{a c}$.

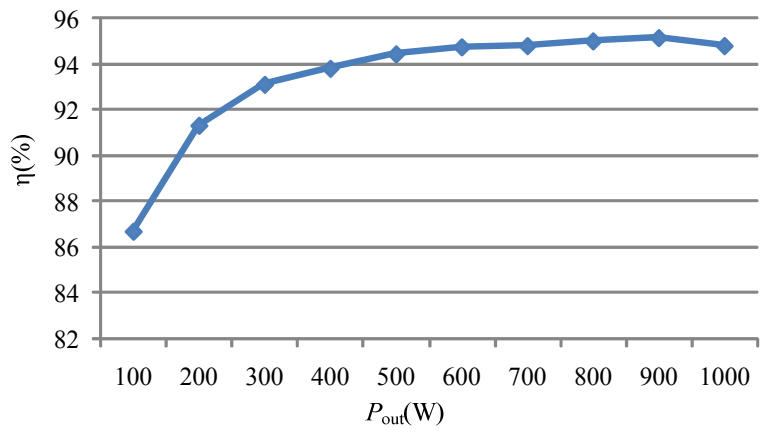

Fig. 13. Measured efficiency of ZVI-TL.

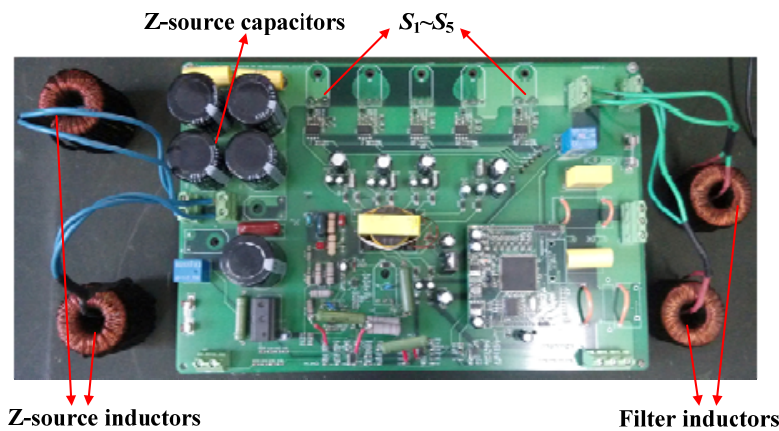

Fig. 14. Photograph of the proposed inverter. mode. Thus, $v_{c m}$ is maintained at approximately $V_{P V} / 2$. The leakage current $i_{c m}$ is successfully limited to a very small value that is less than $70 \mathrm{~mA}$ for the peak value and less than $50 \mathrm{~mA}$ for the rms value. This complies with the DIN V VDE V 0126-1-1 standard.

Fig.10 shows the CM voltage and the leakage current waveforms of the ZVI-TL without a paralleled capacitor. It can be seen that the leakage current with a paralleled capacitor is less than that without a paralleled capacitor.

Fig. 11 shows the dc-link voltage $v_{F F}$, the collector-emitter voltage $v_{S 5}$ of $S_{5}$, and the $Z$-source inductor current $i_{\mathrm{L}}$ waveforms. It is clear that $i_{L}$ increases in the shoot-through mode and decreases in the non-shoot-through mode. In the freewheeling modes, $S_{5}$ is OFF and $v_{S 5}$ is equal to $200 \mathrm{~V}$.

Fig. 12 shows the grid current and voltage waveforms. The grid-connected current is highly sinusoidal and synchronized with the grid voltage. The experimental efficiency of the Z-source PV grid-connected inverter is shown in Fig. 13. The maximum efficiency is $95.15 \%$, including the main circuit, control board, and auxiliary power. Fig. 14 shows a photograph of the proposed inverter.

\section{CONCLUSION}

A modified transformerless Z-source PV grid-connected inverter has been proposed in this paper. The proposed inverter has the following characteristics: (i) a decoupling switch and two reversed-biased diodes are used to eliminate the leakage current, (ii) a modified PWM strategy is implemented, which ensures a single power device switching per state transition, and retain all of the harmonic benefits of conventional modulation strategies, (iii) no shoot-through issue leads to a greatly enhanced reliability, and (iv) a low ac output current distortion can be achieved because there is no dead time. These factors make the modified Z-source inverter suitable for high efficiency and low leakage current transformerless PV grid-connected applications. Finally, experimental results obtained with a $1 \mathrm{~kW}$ hardware prototype verify the effectiveness of the proposed inverter.

\section{ACKNOWLEDGMENT}

This research work was supported by National Natural Science Foundation of China (51207032), Power Electronics Science and Education Development Program of Delta Environmental \& Educational Foundation (DREK2013003), and Fundamental Research Funds for the Central Universities (Grant No. HIT. NSRIF. 2013019).

\section{REFERENCES}

[1] A. Teke, and M. B. Latran, "Review of multifunctional inverter topologies and control schemes used in distributed generation systems," Journal of Power Electronics, Vol. 
14, No. 2, pp. 324-340, Mar. 2014

[2] M. R. Islam, Y. G. Guo, and J. G. Zhu, "A multilevel medium-voltage inverter for step-up-transformer-less grid connection of photovoltaic power plants," IEEE J. Photovoltaics, Vol. 4, No. 3, pp. 881-889, May 2014.

[3] M. Amirabadi, A. Blakrishnan, H. A. Toliyat, and W. C. Alexander, "High-frequency AC-link PV inverter," IEEE Trans. Ind Electron., Vol. 61, No. 1, pp. 281-291, Jan. 2014.

[4] P. R. Prasanna, and A. K. Rathore, "Analysis, design, and experimental results of a novel soft-switching snubberless current-fed half-bridge front-end converter-based PV inverter," IEEE Trans. Power Electron., Vol. 28, No. 7, pp. 3219-3230, Jul. 2014.

[5] K. Deng, J. Y. Zheng, and J. Mei, "Novel switched-inductor quasi-Z-source inverter," Journal of Power Electronics, Vol. 14, No. 1, pp. 11-21, Jan. 2013.

[6] M.-K, Nguyen, Y.-C. Lim, Y.-H. Chang, and C.-J. Moon, "Embedded switched-inductor Z-source inverters," Journal of Power Electronics, Vol. 13, No. 1, pp. 9-19, Jan. 2013.

[7] Y. S. Liu, B. M. Ge, H. Abu-Rub, and F. Z. Peng, "Overview of space vector modulations for three-phase Z-source/quasi-Z-source inverters," IEEE Trans. Power Electron., Vol. 29, No. 4, pp. 2098-2108, Apr. 2014.

[8] F. Bradaschia, M. C. Cavalcanti, P. E. P. Ferraz, F. A. S. Neves, E. C. dos santos, and J. H. G. M. da Silva, "Modulation for three-phase transformerless Z-source inverter to reduce leakage currents in photovoltaic systems," IEEE Trans. Ind Electron., Vol. 58, No. 12, pp. 5385-5395, Dec. 2010.

[9] O. Lopez, F. D. Freijedo, A. G. Yepes, P. fernandez-Comesaa, J. Malvar, R. Teodorescu, and J. Doval-Gansoy, "Eliminating ground current in a transformerless photovoltaic application," IEEE Trans. Energy Convers., Vol. 25, No. 1, pp. 140-147, Mar. 2010.

[10] B. Gu, J. Dominic, J. S, Lai, C. L Chen, T Labella, and B. $\mathrm{F}$ Chen, "High reliability and efficiency single-phase transformerless incverter for grid-connected photovoltaic systems," IEEE Trans. Power Electron., Vol. 28, No. 5, pp. 2235-2245, May 2013.

[11] S. H. Lee, K. T. Kim, J. M. K, and B. H. K, "Single-phase transformerless bi-directional inverter with high efficiency and low leakage current," IET Power Electron., Vol. 7, No. 2, pp. 451-458, 2014.

[12] C. C. Hou, C.C. Shih, P. T. Cheng, and A. M. Hava, "Common-mode voltage reduction pulsewidth modulation techniques for three-phase grid-connected converters," IEEE Trans. Power Electron., Vol. 28, No. 4, pp. 1971-1979, Apr. 2014.

[13] H. F. Xiao, X. P. Liu, and K. Lan, "Zero-voltage-transition full-bridge topologies for transformerless photovoltaic grid-connected inverter," IEEE Trans. Ind Electron., Vol. 61, No. 10, pp. 5393-5401, Oct. 2014.

[14] S. Saridakis, E. Koutroulis, and F. Blaabjerg, "Optimal design of modern transformerless PV inverter topologies," IEEE Trans. Energy Convers., Vol. 28, No. 2, pp. 394-404, Jun. 2013.

[15] B. Yang, W. H. Li, Y. J Gu, W. F. Cui, and X. N. He, "Improved transformerless inverter with commom-mode leakage current elimination for a photovoltaic grid-connected power system," IEEE Trans. Power Electron., Vol. 27, No. 2, pp. 752-762, Feb. 2012.

[16] L. Zhang, K. Su, Y. Xing, and M. Xing, "H6 transformerless full-bridge PV grid-tied inverters," IEEE
Trans. Power Electron., Vol. 29, No. 3, pp. 1229-1238, Mar. 2014

[17] H. F. Xiao, X. P. Liu, and K. Lan, "Optimised full-bridge transformerless photovoltaic grid-connected inverter with low conduction loss and low leakage current," IET Power Electron., Vol. 7, No. 4, pp. 1008-1015, Apr. 2014.

[18] H. F. Xiao, S. J. Xie, Y Chen, and R. H. Huang, "An optimized transformerless photovoltaic grid-connected inverter," IEEE Trans. Ind Electron., Vol. 58, No. 5, pp. 1887-1895, May 2011.

[19] B. J. Ji, J. H. Wang, and J. F. Zhao, "High-efficiency single-phase transformerless PV H6 inverter with hybrid modulation method," IEEE Trans. Ind Electron., Vol. 60, No. 5, pp. 2104-2115, May 2013.

[20] T. Kerekes, R. Teodorescu, P. Rodriguez, G. Vazquez, and E. Aldabas, "A new high-efficiency single-phase transformerless PV inverter topology," IEEE Trans. Ind Electron., Vol. 58, No. 1, pp. 184-191, Jan. 2011.

[21] T. K. S. Freddy, N. A. Rahim, W. P. Hew, and H. S. Che, "Comparison and analysis of single-phase transformerless grid-connected PV inverters," IEEE Trans. Power Electron., Vol. 29, No. 10, pp. 5358-5369, Oct. 2014.

[22] Y. J. Gu, Y. Zhao, B. Yang, C. S. Li, and X. N. He, "Transformerless inverter with virtual DC bus concept for cost-effective grid-connected PV power systems," IEEE Trans. Power Electron., Vol. 28, No. 10, pp. 793-805, Feb. 2013.

[23] S. V. Araujo, P. Zacharias, and R. Mallwitz, "Highly efficient single-phase transformerless inverters for grid-connected photovoltaic systems," IEEE Trans. Ind Electron., Vol. 57, No. 9, pp. 3118-3128, Sep. 2010.

[24] Y. Wang, and R. Li, "Novel high-efficiency three-level stacked-neutral-point-clamped grid-tied inverter," IEEE Trans. Ind Electron., Vol. 60, No. 9, pp. 3766-3774, Sep. 2013.

[25] International Rectifier, IRGP4062D Datasheet, http://www.irf.com/product-info/datasheets/data/irgb4062 dpbf.pdf, 2013.

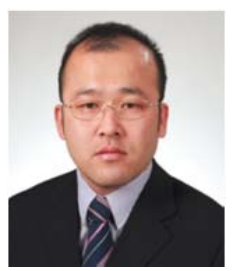

Hongpeng Liu was born in Inner Mongolia, China. He received his B.S. degree in Electrical Engineering from the Harbin University of Science and Technology, Harbin, China, in 2000, and his M.S. and $\mathrm{Ph} . \mathrm{D}$. degrees in Electrical Engineering from the Harbin Institute of Technology, Harbin, China, in 2006 and 2011, respectively. In 2011, he joined the Harbin Institute of Technology as an Assistant Professor in the Department of Electrical Engineering. His current research interests include photovoltaic generation, Micro-grids, and PWM converter/inverter systems.

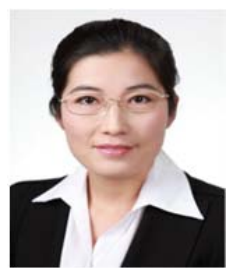

Guihua Liu was born in Shandong Province, China. She received her B.S., M.S. and Ph.D. degrees in Electrical Engineering from the Harbin Institute of Technology, Harbin, China, in 2000, 2005 and 2009, respectively. In 2006, she joined the Harbin Institute of Technology as an Assistant Professor in the Department of Electrical Engineering, where she has been an Associate Professor since 2014. Her current research interests include photovoltaic generation, airconditioning control technology and switching power supplies. 


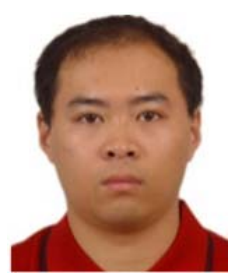

Yan Ran was born in Shandong Province, China. He received his B.S. and M.S. degrees in Electrical Engineering from the Harbin Institute of Technology, Weihai, China, in 2011 and 2013, respectively. He is presently working toward his Ph.D. degree in Electrical Engineering at the Harbin Institute of Technology, Harbin, China. His current research interests include photovoltaic generation, Z-source inverters and energy storage.

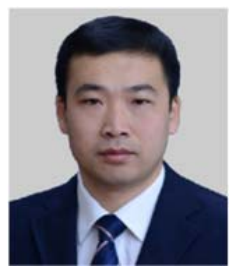

Gaolin Wang was born in Fujian Province, China. He received his B.S., M.S. and Ph.D. degrees in Electrical Engineering from the Harbin Institute of Technology, Harbin, China, in 2002, 2004 and 2008, respectively. In 2009, he joined the Harbin Institute of Technology, as an Assistant Professor in the Department of Electrical Engineering, where he was an Associate Professor from December 2012 to December 2014, and where he has been a Professor since 2015. His current research interests include permanent magnet synchronous motor drives, position sensorless control of AC motors, and digital control of power converters.

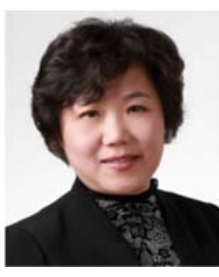

Wei Wang was born in Heilongiiang Province, China. She received her B.S. degree in Automatic Test and Control, her M.S. degree in Electrical Engineering, and her Ph.D. degree in Mechanical Electronic Engineering from the Harbin Institute of Technology, Harbin, China, in 1984, 1990 and 2002, respectively. In 1984, she joined the Harbin Institute of Technology as an Assistant Professor in the Department of Electrical Engineering, where she was an Associate Professor from 1995 to 2003, and where she has been a Professor since 2003. Her current research interests include regenerative energy converter techniques, micro-grids, soft-switching converters, and lighting electronic technology.

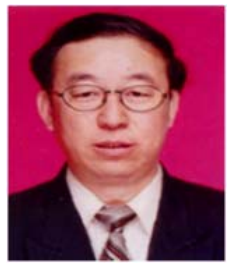

Dianguo Xu was born in Heilongjiang Province, China. He received his B.S. degree in Control Engineering from the Harbin Shipbuilding Engineering Institute, Harbin, China, in 1981, and his M.S. and Ph.D. degrees in Electrical Engineering from the Harbin Institute of Technology (HIT), Harbin, China, in 1984 and 1990, respectively. In 1984, he joined the Harbin Institute of Technology as an Assistant Professor in the Department of Electrical Engineering, where he was an Associate Professor from July 1991 to June 1994, and where he has been a Professor since July 1994. He was the Dean of the School of Electrical Engineering and Automation, HIT, from 2000 to 2010, and was the Assistant President of HIT, from 2010 to 2014. He is now the Vice President of HIT. His current research interests include renewable energy generation technology, power quality mitigation, sensorless vector controlled motor drives, and high performance PMSM servo systems. 